\title{
The modulatory effect of estradiol benzoate on superoxide dismutase activity in the developing rat brain
}

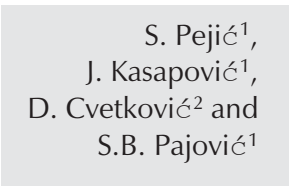

\author{
${ }^{1}$ Laboratory for Molecular Biology and Endocrinology, \\ Vinča Institute of Nuclear Sciences, Belgrade, Yugoslavia \\ ${ }^{2}$ Institute of Zoology, Faculty of Biology, University of Belgrade, \\ Belgrade, Yugoslavia
}

\begin{abstract}
Correspondence

S.B. Pajović

Laboratory for Molecular Biology

and Endocrinology

Vinča Institute for Nuclear Sciences

P.O. Box 522

11001 Belgrade

Yugoslavia

Fax: +38-1-11-455-561

E-mail: pajovic@rt270.vin.bg.ac.yu

....................

Received June 27, 2002

Accepted January 15, 2003

The sensitivity of copper,zinc ( $\mathrm{CuZn}$ )- and manganese (Mn)-superoxide dismutase (SOD) to exogenous estradiol benzoate (EB) was investigated in Wistar rats during postnatal brain development. Enzyme activities were measured in samples prepared from brains of rats of both sexes and various ages between 0 and 75 days, treated $s c$ with $0.5 \mu \mathrm{g} \mathrm{EB} / 100 \mathrm{~g}$ body weight in $0.1 \mathrm{ml}$ olive oil $/ 100 \mathrm{~g}$ body weight, 48 and $24 \mathrm{~h}$ before sacrifice. In females, EB treatment stimulated MnSOD activity on days 0 (66.1\%), $8(72.7 \%)$ and $15(81.7 \%)$. In males, the stimulatory effect of EB on MnSOD activity on day 0 (113.6\%) disappeared on day 8 and on days 15 and 45 it became inhibitory ( 40.3 and $30.5 \%$, respectively). EB had no effect on the other age groups. The stimulatory effect of EB on $\mathrm{CuZnSOD}$ activity in newborn females $(51.8 \%)$ changed to an inhibitory effect on day $8(38.4 \%)$ and disappeared by day 45 when inhibition was detected again $(48.7 \%)$. In males, the inhibitory effect on this enzyme was observed on days $0(45.0 \%)$ and $15(28.9 \%)$, and then disappeared until day 60 when a stimulatory effect was observed (38.4\%). EB treatment had no effect on the other age groups. The sensitivity of MnSOD to estradiol differed significantly between sexes during the neonatal and prepubertal period, whereas it followed a similar pattern thereafter. The sensitivity of CuZnSOD to estradiol differed significantly between sexes during most of the study period. Regression analysis showed that the sensitivity of MnSOD to this estrogen tended to decrease similarly in both sexes, whereas the sensitivity of CuZnSOD showed a significantly different opposite tendency in female and male rats. These are the first reports indicating hormonal modulation of antioxidant enzyme activities related to the developmental process.
\end{abstract}

\section{Introduction}

Antioxidant enzymes such as superoxide dismutase (SOD), catalase (CAT), and glutathione peroxidase (GPx) reduce levels of superoxide radicals $\left(\mathrm{O}_{2}{ }^{-}\right)$and $\mathrm{H}_{2} \mathrm{O}_{2}$, thus protecting cells from oxygen toxicity. Data suggest that estradiol contributes to the physi-
Key words

- Brain

- Brain development

- Estradiol

- Superoxide dismutase 
ovulatory cycle in humans (4), whereas GPx activity in erythrocytes is positively correlated with plasma estradiol levels during the menstrual cycle (5). It has been reported that estradiol influences the expression of SOD in the corpus luteum (6) and significantly alters the activity of CAT (3) and the production of $\mathrm{O}_{2}{ }^{--}$and $\mathrm{H}_{2} \mathrm{O}_{2}(7)$ in rat macrophages.

The regulatory role of estradiol on antioxidant enzymes is more intriguing in light of the hypothesis that reactive oxygen species can act as physiological signaling molecules (8). Namely, there is growing evidence suggesting that $\mathrm{O}_{2}{ }^{--}$and $\mathrm{H}_{2} \mathrm{O}_{2}$ play a number of significant, diverse roles in reproduction (9) and brain development (10). Finally, estrogens function as radical scavengers and inhibit neuronal peroxidation both in vivo and in vitro (11). The marked antioxidant activity of estradiol makes this steroid a candidate for the therapy of neurodegenerative diseases associated with aging (12).

It is well known that estradiol exerts multiple effects on morphogenesis, neuroendocrine function, sex differentiation and neurotransmission during brain development. Also, the importance of antioxidant enzymes in neuroprotection during brain development and aging has been well documented (13-15). Yet, we found no data concerning hormonal modulation of antioxidant enzyme activities during developmental processes. Our previous studies have shown that estradiol benzoate (EB) and progesterone modulate the activities of SOD, GPx, CAT, and glutathione reductase in brain of adult rats (16-18). The inhibition of brain mitochondrial manganese-SOD (MnSOD) activity by EB without affecting cytosol copper,zinc-SOD (CuZnSOD) activity was a response of rats of both sexes.

In the present study we determined whether exogenous EB affects SOD activity during postnatal brain development in rats of both sexes. We postulated that the regulatory role of estradiol as well as its antioxidant activity in developmental processes could be expressed, at least in part, by modulation of
SOD activity and consequently of the levels of $\mathrm{O}_{2}{ }^{--}$and $\mathrm{H}_{2} \mathrm{O}_{2}$.

\section{Material and Methods}

Wistar rats of both sexes and various ages $(0,8,15,30,45,60$ and 75 days $)$ were housed in open colony cages under controlled conditions of temperature $\left(23 \pm 2^{\circ} \mathrm{C}\right)$ and illumination (lights on from 5:00 to 17:00 h), with free access to tap water and laboratory chow. Animals were treated 48 and $24 \mathrm{~h}$ prior to sacrifice with a sc injection of $0.5 \mu \mathrm{g} \mathrm{EB} / 100 \mathrm{~g}$ body weight (ß-estradiol-3-benzoate; Sigma, St. Louis, MO, USA) suspended in $0.1 \mathrm{ml}$ olive oil/100 g body weight. To obtain the experimental group of newborn rats (0 days), the pregnant females received the same dose of EB 48 and $24 \mathrm{~h}$ before delivery (on the 19th and 20th day of pregnancy). Two groups of control animals were either sham-injected or injected $s c$ with $0.1 \mathrm{ml}$ olive oil $/ 100 \mathrm{~g}$ body weight by the same schedule. Animals were sacrificed by decapitation with a guillotine (Harvard Apparatus Inc., Edenbridge, Kent, UK) and the brains were removed immediately for homogenate preparation.

Tissue homogenates were prepared by the method of Rossi et al. (19) and de Waziers and Albrecht (20) where a freezing/defrosting procedure was used instead of sonication. Individual brains were homogenized in a Teflon/ glass homogenizer (Spindler \& Hoyer, Göttingen, Germany) in $0.25 \mathrm{M}$ sucrose buffer containing $50 \mathrm{mM}$ Tris- $\mathrm{HCl}$ and $1 \mathrm{mMEDTA}$, pH 7.4 ( $1 \mathrm{~g}$ tissue per $2 \mathrm{ml}$ buffer). Brain homogenates were vortexed for $30 \mathrm{~s}$ three times, with intermittent cooling on ice, and frozen at $-70^{\circ} \mathrm{C}$ for $20 \mathrm{~h}$ in order to disrupt the cell membranes and release the MnSOD enzyme from mitochondria into crude homogenates. The homogenates were then defrosted at room temperature, vortexed $1 \mathrm{~min}$ and centrifuged in a Beckman L8-80 M ultracentrifuge (Beckman Instruments Inc., Palo Alto, CA, USA) at $124,000 \mathrm{~g}$ for $90 \mathrm{~min}$ at $4^{\circ} \mathrm{C}$. Supernatants were stored at $-20^{\circ} \mathrm{C}$ until use. 
SOD activity was determined by the method of Misra and Fridovich (21). The auto-oxidation of adrenaline to adrenochrome was carried out in $3 \mathrm{ml}$ of $50 \mathrm{mM} \mathrm{Na}_{2} \mathrm{CO}_{3}$ and $100 \mu \mathrm{M}$ EDTA, $\mathrm{pH} 10.2$, at $26^{\circ} \mathrm{C}$. The inhibition of auto-oxidation was monitored at $480 \mathrm{~nm}$. After assaying total SOD activity the samples were treated with $4 \mathrm{mM} \mathrm{KCN}$ in order to inhibit cytosol SOD (22) and subjected again to the enzyme assay as described above. The values thus obtained were considered to be due to MnSOD. Protein concentration in the cytosol was determined by the method of Lowry et al. (23).

Data were analyzed using the statistical packages OriginPro 6.1 and Statistica 5.0. The differences in enzyme activity (U/mg protein) between EB-treated and control groups were determined by the $t$-test. In further analysis, relative values for enzyme activity were used, expressed as percent of the enzyme activity in controls of the same age. Departures of relative values from normal distribution were determined by the Lilliefors and Shapiro-Wilks test. Since the observed variables did not show significant departures from normal distribution, no data transformation was employed. The effects of EB treatment on enzyme activity during development were tested by ANOVA and the Tukey honest significant difference test. A linear regression model with replication was employed in the analyses of the developmental pattern of the response of SOD activity to EB. The slopes of the regression lines for females and males were compared to determine intergender differences in the response of SOD activity.

\section{Results}

Table 1 shows that olive oil treatment significantly inhibited the activity of MnSOD and CuZnSOD on days 0 and 15 in female

Table 1. The activity of manganese (MnSOD)- and copper,zinc-superoxide dismutase (CuZnSOD) in sham-treated control and olive oil-treated control rats of different ages.

\begin{tabular}{|c|c|c|c|c|c|c|c|}
\hline & \multicolumn{7}{|c|}{ Age (days) } \\
\hline & 0 & 8 & 15 & 30 & 45 & 60 & 75 \\
\hline \multicolumn{8}{|l|}{ MnSOD } \\
\hline \multicolumn{8}{|l|}{ Females } \\
\hline Sham-treated & $\begin{array}{c}12.9 \pm 1.3 \\
(5)\end{array}$ & $\begin{array}{c}9.4 \pm 0.5 \\
\text { (7) }\end{array}$ & $\begin{array}{c}17.4 \pm 0.5 \\
(5)\end{array}$ & $11.5 \pm 2.0$ & $\begin{array}{c}10.8 \pm 1.6 \\
(6)\end{array}$ & $\begin{array}{c}12.0 \pm 2.7 \\
(5)\end{array}$ & $\begin{array}{c}6.4 \pm 1.2 \\
(5)\end{array}$ \\
\hline Olive oil-treated & $\begin{array}{c}8.9 \pm 0.9 * \\
(5)\end{array}$ & $10.3 \underset{(6)}{ \pm} 1.6$ & $11.3 \pm \underset{(6)}{ \pm} 1.0^{*}$ & $\begin{array}{c}11.6 \pm 1.9 \\
(7)\end{array}$ & $\begin{array}{c}12.7 \underset{ \pm}{ \pm} 3.2 \\
(5)\end{array}$ & $\begin{array}{c}9.6 \pm 1.9 \\
(5)\end{array}$ & $\begin{array}{c}16.9 \pm 1.2 \\
(5)\end{array}$ \\
\hline \multicolumn{8}{|l|}{ Males } \\
\hline Sham-treated & $11.4 \underset{(6)}{ \pm} 0.9$ & $\begin{array}{c}14.9 \pm 1.6 \\
(5)\end{array}$ & $\begin{array}{c}14.0 \pm 0.5 \\
(5)\end{array}$ & $\begin{array}{c}11.7 \pm \\
(5)\end{array}$ & $\begin{array}{c}20.7 \pm 2.7 \\
(6)\end{array}$ & $\begin{array}{c}19.0 \pm 2.2 \\
(6)\end{array}$ & $\begin{array}{c}19.4 \pm 2.3 \\
(5)\end{array}$ \\
\hline Olive oil-treated & $9.4 \underset{(5)}{ \pm} 1.2$ & $12.2 \pm \underset{(6)}{ \pm} 1.1$ & $\begin{array}{c}12.2 \pm 2.0 \\
(7)\end{array}$ & $11.7 \underset{(6)}{ \pm} 1.9$ & $\begin{array}{c}17.6 \pm 2.1 \\
(5)\end{array}$ & $\begin{array}{c}15.8 \pm 2.1 \\
(6)\end{array}$ & $\begin{array}{c}19.6 \pm 2.6 \\
(5)\end{array}$ \\
\hline \multicolumn{8}{|l|}{ CuZnSOD } \\
\hline \multicolumn{8}{|l|}{ Females } \\
\hline Sham-treated & $\begin{array}{c}20.1 \pm 0.7 \\
(5)\end{array}$ & $\begin{array}{c}25.5 \pm 3.6 \\
\text { (7) }\end{array}$ & $\begin{array}{c}50.7 \pm 4.5 \\
\text { (5) }\end{array}$ & $\begin{array}{c}39.1 \pm 3.6 \\
(6)\end{array}$ & $\begin{array}{c}37.8 \pm \\
(6)\end{array}$ & $\begin{array}{c}51.0 \pm 5.8 \\
(5)\end{array}$ & $\begin{array}{c}36.3 \pm 1.4 \\
(5)\end{array}$ \\
\hline Olive oil-treated & $16.2 \pm 1.4^{*}$ & $27.4 \underset{(6)}{ \pm} 4.2$ & $\begin{array}{c}33.5 \pm 3.8^{*} \\
(6)\end{array}$ & $\begin{array}{c}32.2 \pm 1.6^{*} \\
(7)\end{array}$ & $\begin{array}{c}44.1 \pm \\
\text { (5) }\end{array}$ & $\begin{array}{c}41.0 \pm 1.5 \\
(5)\end{array}$ & $\begin{array}{c}44.2 \pm 4.4 \\
\text { (5) }\end{array}$ \\
\hline \multicolumn{8}{|l|}{ Males } \\
\hline Sham-treated & $\begin{array}{c}23.2 \pm 2.2 \\
(6)\end{array}$ & $\begin{array}{c}26.9 \pm 3.5 \\
\text { (5) }\end{array}$ & $\begin{array}{c}43.0 \pm 3.5 \\
\text { (5) }\end{array}$ & $\begin{array}{c}32.7 \pm 3.1 \\
\text { (5) }\end{array}$ & $\begin{array}{c}51.1 \pm 5.6 \\
(6)\end{array}$ & $\begin{array}{c}39.6 \pm 1.9 \\
(6)\end{array}$ & $\begin{array}{c}34.0 \pm 1.9 \\
(5)\end{array}$ \\
\hline Olive oil-treated & $\begin{array}{c}5.9 \pm 1.5^{*} \\
(5)\end{array}$ & $27.1 \underset{(6)}{ \pm} 2.4$ & $\begin{array}{c}45.9 \pm 3.6 \\
(7)\end{array}$ & $28.4 \underset{(6)}{ \pm} 2.5$ & $\begin{array}{c}47.8 \pm 5.5 \\
\text { (5) }\end{array}$ & $\begin{array}{c}37.1 \underset{(6)}{ \pm} 3.6 \\
(6)\end{array}$ & $34.7 \pm 2.2 .4$ \\
\hline
\end{tabular}


rats, and the activity of CuZnSOD on day 30 when compared to sham-treated controls. In males, olive oil had no effect on MnSOD activity and inhibited the activity of $\mathrm{CuZnSOD}$ on day 0 . To investigate the modulatory role of EB on SOD activities during brain development and to facilitate the comparison between sexes, we report enzyme activity as percent of the values for olive oiltreated controls of the same age.

\section{MnSOD activity in the brain of female and male rats (Figure 1)}

In the brain of female rats EB treatment stimulated MnSOD activity on days 0

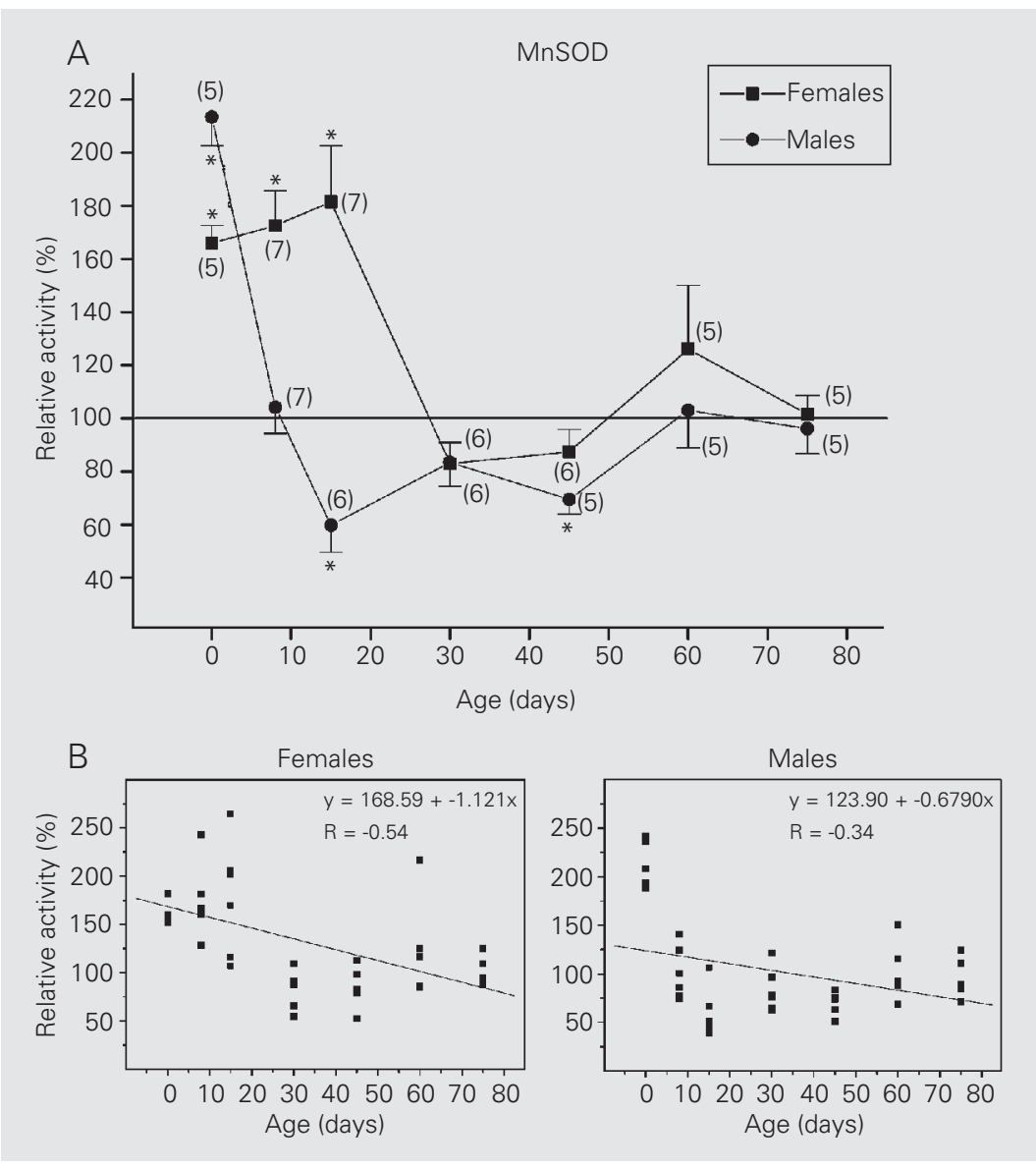

Figure 1. $A$, Effects of estradiol benzoate on manganese-superoxide dismutase (MnSOD) activity in female and male rats of different ages. Data are reported as means \pm SEM as percent of olive oil control values for the number of rats given in parentheses $\left({ }^{*} P<0.05, t\right.$-test). $B$, Scatter-plot of MnSOD activity. $P$ - significance of slope for females $(P<0.001)$ and males $(\mathrm{P}<0.001)$, ANOVA.
$(\mathrm{P}<0.001, t$-test $), 8$ and $15(\mathrm{P}<0.01)$, but had no effect on the activity of the enzyme during further development ( $\mathrm{P}>0.05, t$-test). EB prominently stimulated brain MnSOD activity immediately after birth both in males and in females $(\mathrm{P}<0.001, t$-test $)$. This effect disappeared on day $8(\mathrm{P}>0.05, t$-test $)$ and on day 15 of postnatal development it became inhibitory $(\mathrm{P}<0.05)$ and opposite compared to females. Inhibition was detected again on day 45 ( $\mathrm{P}<0.05, t$-test), while EB seemed to have no effect on the other age groups $(\mathrm{P}>0.05)$.

Time variation in the effect of $\mathrm{EB}$ on MnSOD activity in females (tested by ANOVA and the Tukey test) was statistically significant between days 0,8 and 15 , and days 30 and 45 of postnatal development, with the most significant effect occurring between days 15 and 30 ( $\mathrm{P}<0.001$, Tukey test), when the stimulatory effect of this hormone disappeared. In males, the effect of EB on MnSOD activity showed a highly significant difference between day 0 and all the other time points examined $(\mathrm{P}<0.001$, Tukey test $)$. The effect of the hormone significantly changed between day 8 and day $15(\mathrm{P}<0.05$, Tukey test) when it became inhibitory.

As shown in Figure 1, the sensitivity of MnSOD to estradiol administration differed significantly between sexes during the neonatal and prepubertal period (females $v s$ males for $0,8,15$ days, $\mathrm{P}<0.01, t$-test). During further development this sensitivity followed a similar pattern in female and male rats $(\mathrm{P}>0.05)$. Regardless of the sex differences found for the above mentioned time points during early development, regression analysis (Figure 1B) showed a similar decreasing tendency of MnSOD sensitivity to EB in both sexes during the entire period examined (comparison of regression slopes: $t=-1.06, \mathrm{P}>0.05$ ).

CuZnSOD activity in the brain of female and male rats (Figure 2)

The stimulatory effect of EB on CuZnSOD activity in newborn females 
$(\mathrm{P}<0.05, t$-test) changed to a markedly inhibitory effect on day 8 of postnatal development $(\mathrm{P}<0.01)$, and disappeared by day 45 when strong inhibition of enzyme activity was detected again $(\mathrm{P}<0.001)$. At the age of 60 and 75 days estradiol had no effect on this enzyme ( $\mathrm{P}>0.05, t$-test). In the brain of males, the inhibitory effect of EB on CuZnSOD activity was observed during the early postnatal development, i.e., on days $0(\mathrm{P}<0.01, t$ test) and $15(\mathrm{P}<0.05)$, and then disappeared until day 60 when a stimulatory effect was observed $(\mathrm{P}<0.05)$. At the age of 75 days EB treatment had no effect on CuZnSOD activity $(\mathrm{P}>0.05, t$-test).

The variation with time of the effects of EB on CuZnSOD activity in females showed highly significant differences in inhibition or activation between days 0 and $8(\mathrm{P}<0.001$, Tukey test), 8 and $15(\mathrm{P}<0.01)$, and 15 and $45(\mathrm{P}<0.001)$, when the effect of the hormone was inverted, disappeared and was reestablished again. In males, the effect of EB on the same enzyme was significantly different between days 0,8 and 15 , and day $60(\mathrm{P}<0.001, \mathrm{P}<0.05, \mathrm{P}<0.001$, respectively, Tukey test).

Contrary to MnSOD, for which both inhibition and activation were restricted to the period of early postnatal development, these diverse effects of EB seemed to dominate during the entire period examined in the case of CuZnSOD activity (females vs males for $0,8,15,45,60$ days, $\mathrm{P}<0.02$, $t$-test). Opposite and significantly different tendencies in the response of this enzyme activity to EB between sexes were also shown by regression analysis (Figure 2B, comparison of regression slopes: $t=-3.69, \mathrm{P}<0.001)$.

\section{Discussion}

We used exogenous EB to investigate different developmental periods when modulation of SOD activity by this hormone might be relevant to processes of estradiol-regulated brain differentiation.
We observed that olive oil alone, used as the conventional solvent of EB, reduced SOD activity (24) at certain times during early development (Table 1). This reduction may be related to growing evidence demonstrating the powerful antioxidant properties of olive oil phenolics both in vitro and in vivo (25). In healthy men, ingestion of virgin olive oil increases the incorporation of oleic acid, phenols and vitamin E into low-density lipoprotein (LDL), which increases LDL resistance to oxidation (26). Olive oil phenol hydroxytyrosol reduces $\mathrm{H}_{2} \mathrm{O}_{2}$ generation, $\mathrm{H}_{2} \mathrm{O}_{2}$-induced DNA damage and mRNA levels of GPx in oxidative stress-sensitive human prostate cells (27). It has also been

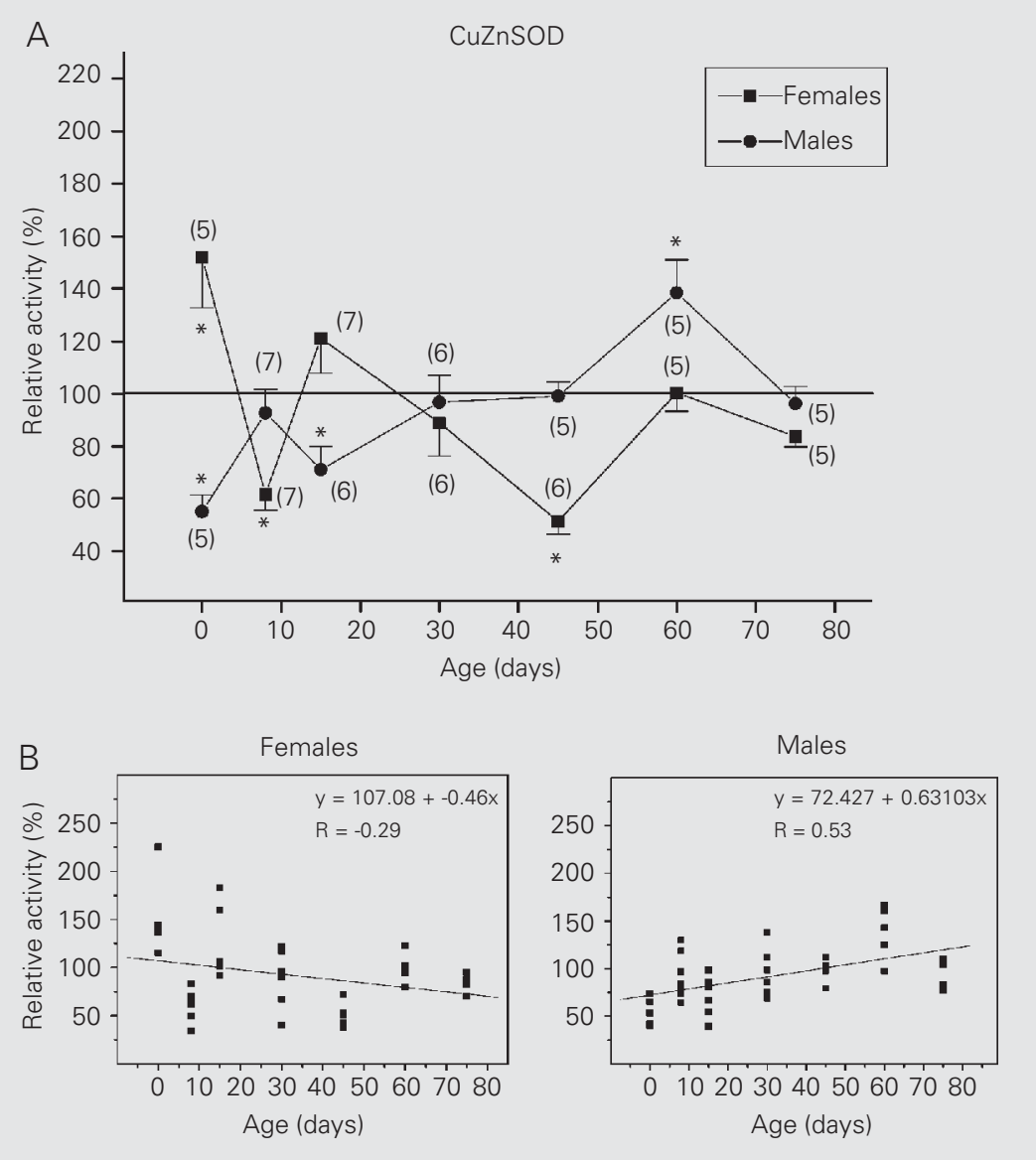

Figure 2. A, Effects of estradiol benzoate on copper,zinc-superoxide dismutase (CuZnSOD) activity in female and male rats of different ages. Data are reported as means \pm SEM as percent of olive oil control values for the number of rats given in parentheses $\left({ }^{*} P<0.05, t\right.$ test). $B$, Scatter-plot of CuZnSOD activity. $P$ - significance of slope for females $(P<0.01)$ and males $(P<0.001)$, ANOVA. 
shown that polyphenol mixtures prepared from olive oil decrease the production of $\mathrm{O}_{2}{ }^{--}$in cultured human promonocyte (28) and that olive oil-fed rats have lower liver CuZnSOD, CAT and GPx activities compared to fish oil-fed rats (29). The reduction of SOD activity by olive oil stopped after day 30 of development and was not observed in adult rat brain (30). This could be due to the marked perturbations in oxidative metabolism and lipid composition during differentiation. Namely, the increased degree of lipid unsaturation demonstrated early during development has been suggested to provide antioxidative protection at the time when antioxidant enzyme defenses are low (31).

When examining the sensitivity of brain SOD to exogenous EB during postnatal development we applied the hormone dose used in studies of its feedback effect on neonatal and infantile rats of both sexes $(32,33)$. EB treatment of the pregnant female rat immediately before delivery increased the activity of both SOD in the brain of female neonates, particularly MnSOD. In the brain of male neonates, strong stimulation of MnSOD activity significantly exceeded the reduction of CuZnSOD activity, representing the most intensive SOD response to EB during the examined developmental period. This indicates that the stimulating effects of EB on brain SOD activities in newborn pups coincided with the high serum estradiol levels found in the neonates (aged 0 and 1 days) of both sexes, which were significantly higher than the maximal values observed in adult rats (34). Since the increased SOD activity in the brain and other tissues of rats during the perinatal period is often related to the transition of newborns from a relatively hypoxic to a hyperoxic environment $(10,35)$, these data suggest a possible influence of estradiol on the SOD response to antioxidant stress induced by delivery.

Although there was a difference in the effects of EB on MnSOD and CuZnSOD activities at the same age, the intragender developmental profile of both SOD responses showed similar increases, stagnations and falls, with the exception of day 8 in females and day 0 in males. This indicates a different mechanism of mitochondrial and cytosol enzyme regulation by exogenous EB during most of the developmental period examined, with a certain degree of time synchronization in their regulation. Previous findings also indicated that during the postnatal development of rats, MnSOD and CuZnSOD activities often do not correlate with one another or with activities of other antioxidant enzymes, and do not synchronously follow the increase of aerobic brain metabolism $(13,14,36)$. Mavelli et al. (13) concluded that two types of SOD respond with a distinct "time constant" to brain differentiation, pointing to a distinct mechanism of regulation.

In contrast, the sensitivity of both SOD to EB significantly differed between sexes during the infantile and early pubertal period of development, and then, beginning on day 30 , it acquired a similar general pattern. This shift in SOD response to EB coincides with the stabilization of plasma estradiol levels around day 30 to the values similar to those of adult rats, after significant oscillations during the first four weeks of postnatal life (34). Also, high levels of endogenous estradiol on days 0,8 and 15 and significantly lower levels on days 30 and 45 (34) correspond to a decreasing sensitivity of both SOD to EB in females and of only MnSOD in males during the same period of development. However, different effects of exogenous EB on SOD activity in females and males, as well as opposite tendencies in MnSOD and CuZnSOD sensitivity in males, are less probably the consequence of changes solely in serum estradiol level, since there is a similar developmental profile of this hormone in rats of both sexes (34). If these effects of EB are mediated by estradiol receptors (ER), asynchronous expression of 
$E R \alpha$ (37) and possibly ERß forms in the brain of female and male rats during development, as well as the possibility of differential transcription activity of ER $\alpha$ and $E R \beta$ through the same regulatory site (38) could be the cause of the observed sex difference in SOD response to EB. On the other hand, different neuroprotective effects of pharmacological and physiological doses of estradiol on $\mathrm{H}_{2} \mathrm{O}_{2}$, glutamate and $\mathrm{B}$-amyloid peptide toxicity (mediated by $\mathrm{H}_{2} \mathrm{O}_{2}$ ) operate through ER-independent mechanisms (12). It is possible that estradiol by the same mechanisms influences not only the neurotoxic, but also the physiological levels of $\mathrm{H}_{2} \mathrm{O}_{2}$, thus modulating SOD activities by changing the enzyme product level. Still, we found no data concerning sex dependence in the ER-independent mechanisms of the neuroprotective and antioxidant effects of estradiol.

Some of the activities of antioxidant enzyme are synergistically coordinated in their response to increased aerobic metabolism during brain development, while others are independently regulated (36). Similar findings, together with the observation of increased transcriptional activity of NF- $\kappa \mathrm{B}$ by increased $\mathrm{H}_{2} \mathrm{O}_{2}$ levels, led de Haan et al. (10) to postulate a role of reactive oxygen species in normal development. Namely, nonsynchronization of antioxidant enzyme activities during development could be related to the tissue's need to produce reactive oxygen species for the selective gene transcription via activation of transcription factors, rather than solely for its antioxidant defense re- quirements. New data on the role of reactive oxygen species in intracellular signaling of transcription, cell proliferation and growth (8) support this assumption. In the light of this, the intergender difference in developmental sensitivity of brain SOD to exogenous EB indicates that estradiol could have a differential influence on females and males not only in $\mathrm{O}_{2}{ }^{--}$detoxification, but also in fine regulation of nontoxic levels of $\mathrm{O}_{2}{ }^{--}$and $\mathrm{H}_{2} \mathrm{O}_{2}$ as secondary messengers in the mitochondrial and cytosol compartment during development.

Considering the pleiotropic influences of estradiol on brain development in females and in males as a metabolite of testosterone (39), sex-specific modulation of SOD by this hormone during the infantile and prepubertal period could contribute to establishing sex-related brain morphology and function. This sex specificity decreased during puberty and adult development, possibly due to the more similar later physiological role of EB modulation of SOD in the differentiation of the female and male brain.

The developmental intra- and intergender influences of EB on SOD activity shown in the present study suggest the contribution of this estrogen to protection against oxidative stress and to the production of signals selectively needed for different periods of brain development. Since the hormonal modulation (40) and the sex specificity of antioxidant enzyme activity (2) were related only to aging, these are the first data indicating hormonal modulation of antioxidant enzymes related to development.

\section{References}

1. Guemouri L, Artur Y, Herbeth B, Jeandel C, Cuny G \& Siest G (1991). Biological variability of superoxide dismutase, glutathione peroxidase and catalase in blood. Clinical Chemistry, 37: 1932-1937.

2. Rikans LE, Moore DR \& Snowden CD (1991). Sex dependent differences in the effects of aging on antioxidant defense mechanisms of rat liver. Biochimica et Biophysica Acta, 1074: 195-200.

3. Azevedo RB, Lacava ZGM, Miyasaka CK, Chavez SB \& Curi R (2001). Regulation of antioxidant enzyme activities in male and female rat macrophages by sex steroids. Brazilian Journal of Medical and Biological Research, 34: 683-687.

4. Shiotani M, Noda Y, Narimoto K, Imai K, Mori T, Fujimoto K \& Ogawa K (1991). Immunohistochemical localization of superoxide dismutase in the human ovary. Human Reproduction, 6: 1349-1353.

5. Massafra C, Gioia D, De Felice C, Picciolini E, De Leo V, Bonifazi M \& Bernabei A (2000). Effects of estrogens and androgens on erythrocyte antioxidant superoxide dismutase, catalase and glutathione 
peroxidase activities during the menstrual cycle. Journal of Endocrinology, 167: 447-452.

6. Sugino N, Hirosawa-Takamori M, Zhong L, Telleria CM, Shiota K \& Gibori G (1998). Hormonal regulation of copper-zinc superoxide dismutase and manganese superoxide dismutase messenger ribonucleic acid in the rat corpus luteum: Induction by prolactin and placental lactogens. Biology of Reproduction, 59: 599-605.

7. Chao T, Van Alten PV \& Valter RJ (1994). Steroid sex hormones and macrophage function: modulation of reactive oxygen intermediates and nitrite release. American Journal of Reproductive Immunology, 32: 43-52.

8. Finkel T (1998). Oxygen radicals and signaling. Current Opinion in Cell Biology, 10: 248-253.

9. Behrman HR, Riley JCM \& Aten RF (1993). Reactive oxygen species and ovarian function. In: Adashi EY \& Leung PCK (Editors), The Ovary. Raven Press Ltd., New York, NY, USA, 455-471.

10. de Haan JB, Tymms MJ, Cristiano F \& Kola I (1994). Expression of copper/zinc superoxide dismutase and glutathione peroxidase in organs of developing mouse embryos, fetuses, and neonates. Pediatric Research, 35: 188-196.

11. Brinton RD \& Yamazaki RS (1998). Advances and challenges in the prevention and treatment of Alzheimer's disease. Pharmacological Research, 15: 386-398.

12. Simpkins JW, Rabbani O, Shi J, Panickar KS, Green PS \& Day AL (1998). A system for the brain-enhanced delivery of estradiol: An assessment of its potential for the treatment of Alzheimer's disease and stroke. Pharmazie, 53: 505-511.

13. Mavelli I, Rigo A, Federico R, Ciriolo MR \& Rotilio G (1982). Superoxide dismutase, glutathione peroxidase and catalase in developing rat brain. Biochemical Journal, 204: 535-540.

14. Del Maestro R \& McDonald W (1987). Distribution of superoxide dismutase, glutathione peroxidase and catalase in developing rat brain. Mechanisms of Ageing and Development, 41: 29-38.

15. Mariucci G, Ambrosini MV, Colarieti L \& Bruschelli G (1990). Differential changes in $\mathrm{Cu}, \mathrm{Zn}$ and $\mathrm{Mn}$ superoxide dismutase activity in developing rat brain and liver. Experientia, 46: 753-755

16. Pajović S, Nikezić G \& Martinović JV (1993). Effects of ovarian steroids on superoxide dismutase activity in the rat brain. Experientia, 49: 73-75.

17. Pajović S, Saičić ZS, Spasić MB, Petrović VM \& Martinović JV (1996). Effects of progesterone and estradiol benzoate on superoxide dismutase activity in the brain of male rats. Experientia, 52: 221 224.

18. Pajović SB, Saičić ZS, Spasić MB, Petrović VM \& Martinović JV (1999). Effects of progesterone and estradiol benzoate on glutathione dependent antioxidant enzyme activities in the brain of female rats. General Physiology and Biophysics, 18: 35-44.

19. Rossi MA, Cecchini G \& Dianzani MU (1983). Glutathione peroxidase, glutathione reductase and glutathione transferase in two different hepatomas and in normal liver. International Research Communications System. Medical Science, 11: 805.

20. de Waziers I \& Albrecht R (1987). The effects of vitamin A nutritional status on glutathione, glutathione transferase and glutathione peroxidase activities in rat intestine. Experientia, 43: 394-395.

21. Misra HP \& Fridovich I (1972). The role of superoxide anion in the autooxidation of epinephrine and a simple assay for superoxide dismutase. Journal of Biological Chemistry, 247: 3170-3175.

22. Geller BL \& Winge DR (1983). A method for distinguishing Cu,Znand Mn-containing superoxide dismutases. Analytical Biochemistry, 128: 86-92.
23. Lowry OH, Rosebrough NJ, Farr AL \& Randall RJJ (1951). Protein measurement with the Folin phenol reagent. Journal of Biological Chemistry, 193: 265-275.

24. Pejić S, Kasapović J \& Pajović SB (1999). Effects of olive oil on superoxide dismutase activity in brain of newborn and young female rats. Physiological Research, 48: 297-301.

25. Visioli F, Poli A \& Galli C (2002). Antioxidant and other biological activities of phenols from olives and olive oil. Medicinal Research Reviews, 22: 65-75.

26. Gimeno E, Fito M, Lamuela-Raventos RM, Castellote Al, Covas M, Farre M, de La Torre-Boronat MC \& Lopez-Sabater MC (2002). Effect of ingestion of virgin olive oil on human low-density lipoprotein composition. European Journal of Clinical Nutrition, 56: 114120.

27. Quiles JL, Farquharson AJ, Simpson DK, Grant I \& Wahle KW (2002). Olive oil phenolics: effects on DNA oxidation and redox enzyme mRNA in prostate cells. British Journal of Nutrition, 88: 225-234.

28. Leger CL, Kadiri-Hassani N \& Descomps B (2000). Decreased superoxide anion production in cultured human promonocyte cells (THP1) due to polyphenol mixtures from olive oil processing wastewaters. Journal of Agricultural and Food Chemistry, 48: 5061-5067.

29. Ruiz-Gutierrez V, Perez-Espinosa A, Vazquez CM \& Santa-Maria C (1999). Effects of dietary fats (fish, olive and high-oleic-acid sunflower oils) on lipid composition and antioxidant enzymes in rat liver. British Journal of Nutrition, 82: 233-241.

30. Pajović SB, Kasapović J \& Martinović J (1997). Superoxide dismutase activities in different tissues of female rats treated with olive oil. Physiological Research, 46: 381-384.

31. Allen RG \& Balin AK (1989). Oxidative influence on development and differentiation: an overview of a free radical theory of development. Free Radical Biology and Medicine, 6: 631-661.

32. Goldman BD \& Gorski RA (1971). Effects of gonadal steroids on the secretion of LH and FSH in neonatal rats. Endocrinology, 89: 112115.

33. Rodriguez-Sierra JF \& Clough RW (1987). Sexual dimorphism in the synaptogenic effect of estradiol in prepubertal rats. Synapse, 1: 258264.

34. Dohler KD \& Wuttke W (1975). Changes with age in levels of serum gonadotropins, prolactin, and gonadal steroids in prepubertal male and female rats. Endocrinology, 97: 898-907.

35. Tanswell AK \& Freeman BA (1984). Pulmonary antioxidant enzyme maturation in the fetal and neonatal rat. I. Developmental profiles. Pediatric Research, 18: 584-587.

36. Ninfali P, Aluigi G \& Pompella A (1998). Postnatal expression of glucose-6-phosphate dehydrogenase in different brain areas. Neurochemical Research, 23: 1197-1204.

37. Yokosuka M, Okamura H \& Hayashi S (1997). Postnatal development and sex difference in neurons containing estrogen receptoralpha immunoreactivity in the preoptic brain, the diencephalon, and the amygdala in the rat. Journal of Comparative Neurology, 389: 8193.

38. Paech K, Webb P, Kuiper GGJM, Nilsson S, Gustafsson J-A, Kushner PJ \& Scanian TS (1997). Differential ligand activation of estrogen receptors ERalpha and ERbeta at AP1 sites. Science, 277: 15081510.

39. MacLusky NJ \& Naftolin F (1981). Sexual differentiation of the central nervous system. Science, 211: 1294-1311.

40. Bolzan AD, Brown OA, Goya RG \& Bianchi MS (1995). Hormonal modulation of antioxidant enzyme activities in young and old rats. Experimental Gerontology, 30: 169-175. 